\title{
PENGEMBANGAN MODUL PEMBELAJARAN TEORI MUSIK PADA PRODI PENDIDIKAN MUSIK FAKULTAS BAHASA DAN SENI UNIVERSITAS NEGERI PADANG
}

\section{THE DEVELOPMENT OF MUSIC THEORY LEARNING MODULE IN MUSIC EDUCATION PROGRAM AT FACULTY OF LANGUAGE AND ART UNIVERSITAS NEGERI PADANG}

\author{
Agung Dwi Putra'; Irdhan Epria Darma Putra²; Robby Ferdian ${ }^{3}$ \\ ${ }^{1}$ Program Studi Pendidikan Musik, Universitas Negeri Padang \\ ${ }^{(*)} \bowtie$ (e-mail) agung.2nd.son@gmail.com ${ }^{1} ;$ kirbyirdhan@gmail.com²; robbyferdian1991@gmail.com ${ }^{3}$
}

\begin{abstract}
Abstrak
Prodi Pendidikan Musik UNP tentu harus mampu memfasilitasi kebutuhan pembelajaran teori musik bagi mahasiswa secara optimal, mengingat perannya yang sangat fundamental. Namun faktanya, Prodi Pendidikan Musik UNP sampai saat ini (tahun kedua berjalan) masih belum memiliki modul pembelajaran teori musik yang dapat digunakan dalam proses pembelajaran teori musik. Pertimbangan untuk mengembangkan modul pembelajaran teori musik interaktif dengan memperhatikan gaya hidup mahasiswa saat ini, menjadi kunci bagi penelitian ini. Dalam penelitian ini, tim peneliti menerapkan metode penelitian dan pengembangan model ADDIE karena diyakini efektif untuk digunakan sebagai pengembangan modul pembelajaran interaktif
\end{abstract}

Kata kunci: teori musik, modul pembelajaran interaktif, ADDIE.

\begin{abstract}
UNP Music Education Study Program certainly must be able to facilitate the learning needs of music theory for students optimally, given its very fundamental role. But in fact, the UNP Music Education Study Program (the second year running) still does not have a music theory learning module that can be used in the process of learning music theory. The consideration for developing an interactive music theory learning module by paying attention to the current student lifestyle is the key to this research. In this study, the research team applied the research method and development of the ADDIE model because it was believed to be effective to be used as the development of an interactive learning module
\end{abstract}

Keywords: music theory, interactive learning module, ADDIE. 


\section{Pendahuluan}

Salah satu wujud pelayanan optimal Pendidikan Tinggi adalah menciptakan proses pembelajaran yang konstruktif dan menyenangkan bagi mahasiswa. Sebagai Prodi baru, Prodi Pendidikan Musik UNP tentu masih perlu menata, mengadaptasi, dan terus mengembangkan pelayanannya terkait dengan proses pembelajaran yang diperuntukkan bagi mahasiswanya pada setiap mata kuliah. Berpijak dari hal ini, maka perlu dicermati dengan saksama mata kuliah apakah di Prodi Pendidikan Musik yang perlu segera mendapat perhatian khusus untuk dijadikan acuan dalam proses pembelajaran yang saling berkesinambungan. Dengan kata lain, urgensitas mata kuliah tersebutlah yang laik dikedepankan tanpa tendensi mengesampingkan mata kuliah lainnya.

Dari sekian banyak mata kuliah yang ditawarkan Prodi Pendidikan Musik UNP, mata kuliah Teori Musik I merupakan mata kuliah fundamental sebagai gerbang awal untuk mengonstruksi pemahaman mahasiswa terhadap berbagai fenomena musikal serta relevansinya dengan ilmu kependidikan secara mendasar. Itulah sebabnya mata kuliah ini ditempatkan pada tahun pertama perkuliahan secara berjenjang, yakni di semester I dan II (Teori Musik II). Sudah dapat dipastikan apabila seorang mahasiswa gagal menempuh mata kuliah ini maka ia tidak akan dapat melanjutkan menuju mata kuliah esensial lainnya seperti; mata kuliah Harmoni, Kontrapung, Aransemen, Orkestrasi, Analisis Musik, dan Komposisi Musik. Selain itu, dampak lainnya adalah mahasiswa akan kesulitan untuk memahami mata kuliah Strategi Pembelajaran Musik, dan Media Pembelajaran Musik yang masih syarat akan pembahasan teori musik.

Mata kuliah Teori Musik I sebagai garda depan mata kuliah lainnya di Prodi Pendidikan Musik UNP tentu harus mampu memfasilitasi kebutuhan pembelajaran teori musik bagi mahasiswa secara optimal, mengingat perannya yang sangat fundamental. Namun faktanya, Prodi Pendidikan Musik UNP sampai saat ini (tahun kedua berjalan) masih belum memiliki modul pembelajaran teori musik yang dapat digunakan dalam proses pembelajaran teori musik. Oleh karenanya, tim peneliti sangat tertarik mengkaji dan meneliti mata kuliah ini untuk dapat mengembangkan bahan ajarnya menjadi sebuah modul pembelajaran yang menarik, sistematis, konstruktif, interaktif, serta akrab dengan gaya hidup mahasiswa saat ini yang cenderung visual, tidak literal. Pertimbangan untuk mengembangkan modul pembelajaran teori musik interaktif dengan memerhatikan gaya hidup mahasiswa saat ini, menjadi kunci bagi penelitian ini.

Berdasarkan alur tersebut, maka artikel ini diberi judul "Pengembangan Modul Pembelajaran Teori Musik I Pada Program Studi Pendidikan Musik Fakultas Bahasa dan Seni Universitas Negeri Padang", guna mempertegas urgensitas sebuah modul pembelajaran teori musik interaktif di lingkungan Prodi Pendidikan Musik UNP. Penelitian ini dirancang untuk menjawab kebutuhan akan pentingnya suatu modul pembelajaran pada mata kuliah teori musik I.

\section{Metode}

Penelitian ini termasuk ke dalam penelitian pengembangan (Research and Develompent) yang bertujuan menghasilkan produk berupa modul pembelajaran teori musik interaktif dengan pemanfaatan kanal YouTube sebagai pelengkapnya. Pendekatan yang digunakan dalam penelitian ini menggunakan model Analysis, Design, Development, Implementation, Evaluation (ADDIE). Model ini dikembangkan oleh Dick dan Carry pada tahun 
1996 yang diyakini sangat sesuai apabila digunakan untuk mengembangkan suatu modul pembelajaran.

Penelitian ini dilaksanakan dan diujicobakan dalam lingkungan Program Studi Pendidikan Musik UNP, khususnya pada mata kuliah Teori Musik. Data yang diolah dalam penelitian ini adalah data primer dari lembar hasil observasi, pedoman wawancara, serta angket yang diberikan kepada responden dan validator di lokasi penelitian. Populasi dalam penelitian ini adalah mahasiswa Prodi Pendidikan Musik UNP. Responden yang dimintai keterangannya adalah berjumlah 30 orang mahasiswa dengan tiga jenis sampel (10 orang dari angkatan 2016, 10 orang dari angkatan 2017, dan 10 orang dari angkatan 2018). Sedangkan validator penelitian terdiri dari satu orang ahli desain pembelajaran dan satu orang ahli media pembelajaran di lingkungan FBS UNP.

Instrumen dan teknik pengumpulan data dalam penelitian ini adalah lembar observasi, untuk melihat tanggapan responden terhadap rancangan modul yang diujicobakan; pedoman wawancara, untuk melihat tanggapan responden terhadap rancangan modul yang diujicobakan; dan angket, untuk memperoleh data dari responden dan validator mengenai pendapat serta komentar tentang kelayakan modul pembelajaran yang diujicobakan. Sedangkan teknik analisis data dalam penelitian ini dilakukan dengan cara mengorganisasi data, mengklasifikasikan data, dan menyimpulkan data. Data yang berasal dari angket kemudian diolah menggunakan skala Likert.

\section{Hasil dan Pembahasan}

Skema dari alur penelitian yang dijalani oleh tim peneliti dapat dilihat pada gambar di bawah ini:

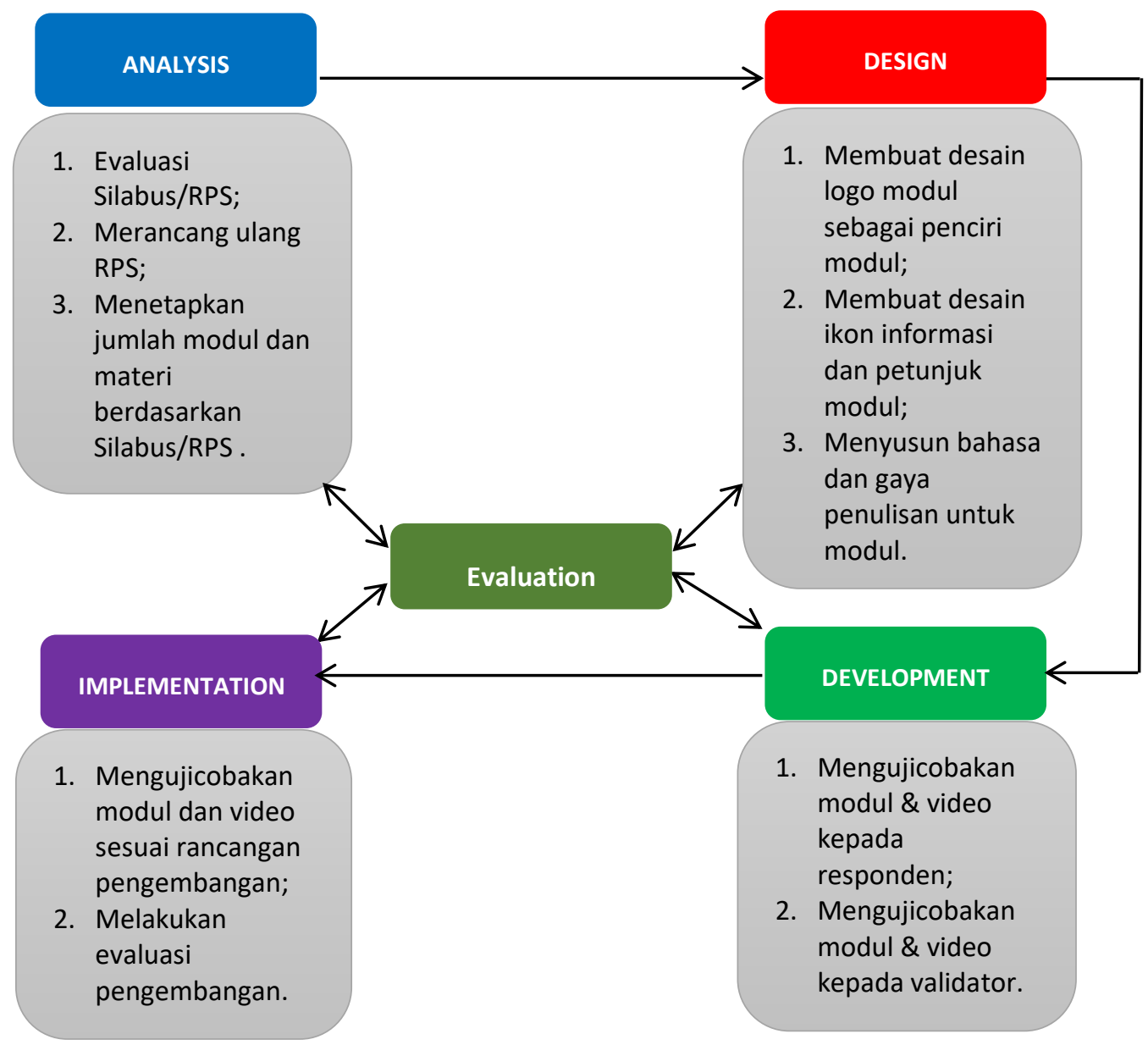

Gambar 1. Skema Penelitian 


\section{Temuan Hasil wawancara}

Sebelum tahap ini dijalani, tim peneliti melakukan wawancara terstruktur kepada lima orang mahasiswa di Prodi Pendidkan Musik UNP. Tujuan wawancara tersebut adalah untuk menggali informasi mahasiswa atas alasan-alasannya memilih buku bacaan, khususnya buku Teori Musik. Hasil dari wawancara tersebut menunjukkan bahwa seluruh mahasiswa yang diwawancarai memilih buku Teori Musik dalam format modul pembelajaran yang lengkap dengan gambar dan ikon-ikon tertentu. Agar memberikan informasi lebih jelas, hasil wawancara mahasiswa tersebut tim peneliti simpulkan melalui tabel di bawah ini:

Table 1. Temuan Wawancara

\begin{tabular}{|c|l|c|}
\hline \multicolumn{2}{|c|}{ KESIMPULAN HASIL WAWANCARA } \\
\multicolumn{1}{|c|}{ KEPADA 5 ORANG MAHASISWA PRODI PENDIDIKAN MUSIK UNP } \\
MENGENAI BUKU TEORI MUSIK DALAM FORMAT MODUL
\end{tabular}

2. Temuan Desain Logo dan Ikon

a. Logo

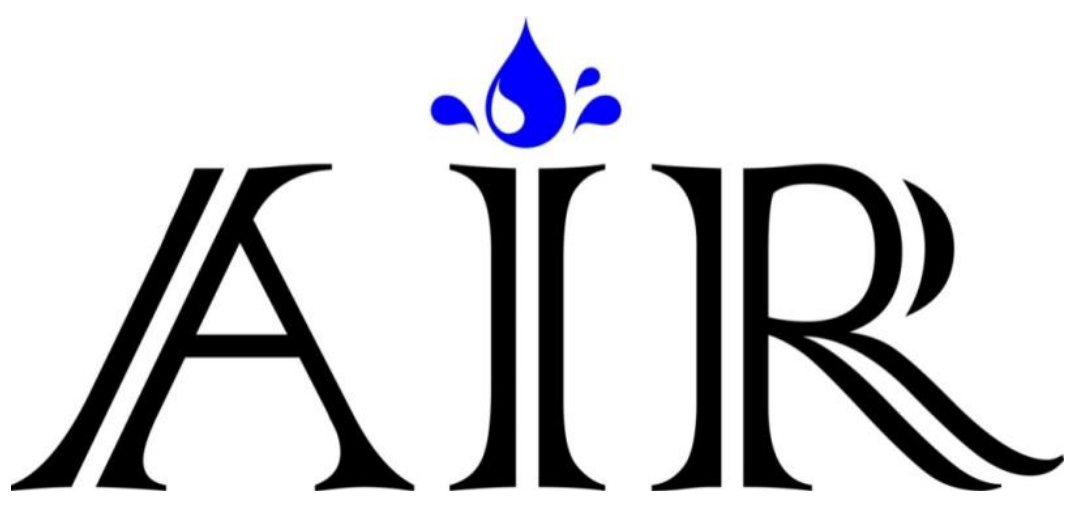

Gambar 2. Logo Modul 
Logo di atas merupakan rancangan yang disepakati oleh tim peneliti dan diyakini mampu mewakili visi dari modul yang akan dikembangkan. Logo di atas menggunakan desain sekumpulan huruf yang menjadi singkatan dari masing-masing nama tim peneliti, yakni: Agung, Irdhan, dan Robby (AIR). Jenis desain huruf yang digunakan memiliki kesan seperti riak air karena tim peneliti melakukan penyesuaian dengan singkatan dari logo, yaitu AIR. Identitas bernuansa air tersebut kemudian diperkuat dengan desain titik pada huruf "i". Titik tersebut di desain sedemikian rupa sehingga berbentuk seperti tetesan air.

Makna yang terkandung dari logo tersebut diambil dari pribahasa Sunda yang menyebutkan bahwa "Cikaracak ninggang batu laun-laun jadi legok". Artinya, tetesan air yang jatuh di atas batu secara perlahan dan terus menerus, pasti menimbulkan batu menjadi lekuk (cekung). Hal ini sekaligus menjadi visi dari modul yang tim peneliti kembangkan agar mampu menyajikan pengalaman belajar bagi penggunanya secara perlahan, berurutan, sistematis namun pasti. Pada sisi lain, tim peneliti memiliki keyakinan bahwa proses belajar pada seseorang harus dijalani "setetes demi setetes" (tahapan demi tahapan) agar terbentuk pemahaman yang utuh dan berkelanjutan.

b. Ikon

Ikon merupakan petunjuk atau tanda yang diwakili oleh gambar, nama, atau elemen grafis tertentu. Misalnya, tombol "like" pada fitur Facebook (diwakili oleh gambar jempol yang diangkat) untuk menunjukkan ketertarikan seseorang ketika melihat posting tertentu. Dengan kata lain, ikon bermakna denotatif sedangkan logo bermakna konotatif. Ikon berfungsi sebagai tanda yang memberikan informasi atau petunjuk tertentu, sedangkan logo berfungsi sebagai simbol yang mengandung pesan atau informasi tertentu. Selain itu, kehadiran ikon pada modul akan memancing ketertarikan pengguna modul. Dalam modul pembelajaran teori musik ini, tim peneliti memutuskan untuk menggunakan ikon-ikon seperti tampak berikut ini:

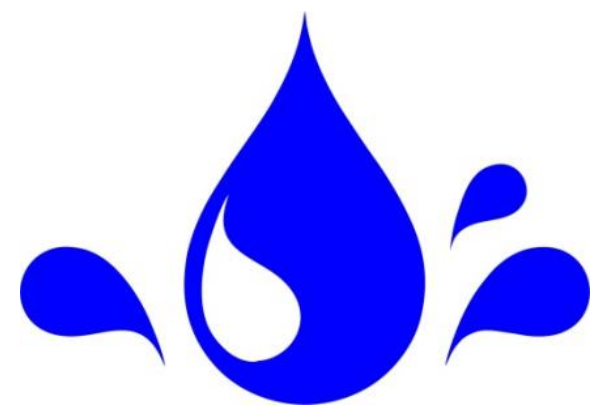

Gambar 3. Ikon Informasi Materi

Ikon di atas ditampilkan pada seluruh bagian awal modul sebagai petunjuk informasi materi yang akan dibahas. Ikon di atas diambil dari "titik pada huruf i" pada logo AIR. Pemilihan ikon ini berdasarkan rasionalitas bahwa materi yang disampaikan dalam modul selalu bertahap. Tahap demi tahap, diibaratkan dengan setetes demi setetes air yang jatuh. 


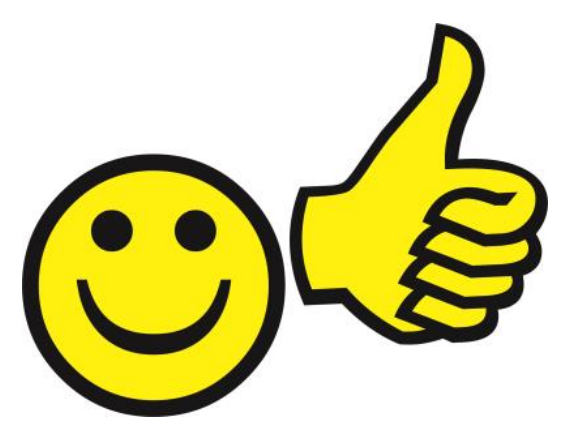

Gambar 4. Ikon Pesan Motivasi

Ikon di atas ditampilkan pada setiap bagian modul sebagai informasi penyemangat, pengingat, dan motivasi yang diambil dari pemaknaan setiap bahasan materi. Pemilihan ikon ini berdasarkan rasionalitas bahwa pengguna modul merupakan pembelajar yang menyenangkan dan senantiasa semangat mengelaborasi setiap bahasan materi.

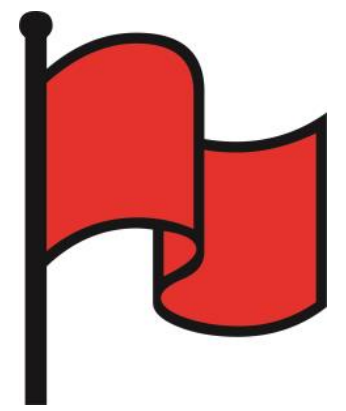

Gambar 5. Ikon Rangkuman Materi

Ikon di atas ditampilkan pada setiap bagian modul sebagai tanda untuk menginformasikan rangkuman materi dalam setiap modul. Dengan adanya rangkuman, pengguna modul dapat mengulas kembali inti materi yang telah dipelajarinya di dalam modul.

Pemilihan ikon di atas berdasarkan rasionalitas bahwa bendera merah merupakan tanda agar pada bagian tersebut pengguna modul sebaiknya berhenti sementara waktu sembari memperhatikan hal-hal penting yang telah dipelajarinya. Hal-hal penting tersebut merupakan informasi yang disajikan dalam format rangkuman materi yang telah dipelajari.

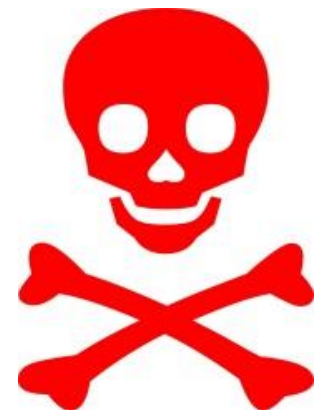

Gambar 6. Ikon Istirahat Sejenak

Ikon di atas ditampilkan pada setiap bagian modul yang bahasannya dianggap panjang dan membutuhkan konsentrasi ekstra. Pemilihan ikon ini berdasarkan rasionalitas bahwa pengguna modul harus melakukan rehat sejenak sebelum melanjutkan kembali pembelajaran. Dengan rehat sejenak, maka pembelajaran dapat berlangsung optimal dan tetap menyenangkan, karena pengguna modul tidak memaksakan dirinya hingga lelah. 


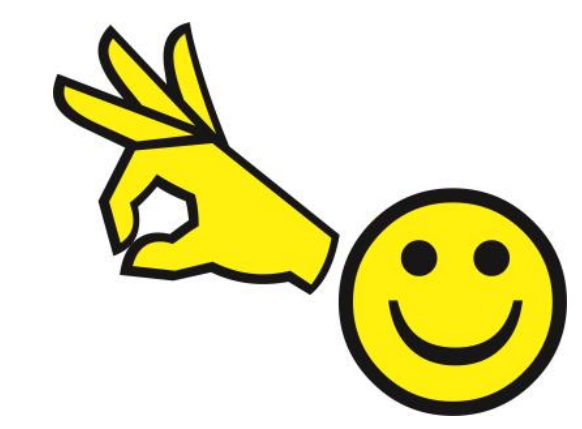

Gambar 7. Ikon Informasi Tambahan

Ikon di atas ditampilkan pada setiap bagian akhir modul sebagai antisipasi pertanyaan tambahan yang mungkin ditanyakan oleh pengguna. Pemilihan ikon ini berdasarkan rasionalitas bahwa pengguna modul tidak dilarang jika memiliki rasa penasaran yang lebih ketika mempelajari suatu materi. Keingintahuan yang tinggi merupakan salah satu ciri bahwa seorang pembelajar bersungguh-sungguh dalam mempelajari sesuatu, dan modul ini memfasilitasi jawaban atas kemungkinan munculnya kegelisahan-kegelisahan tersebut.

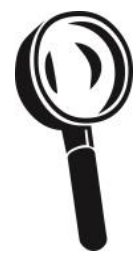

Gambar 8. Ikon Glosarium

Ikon di atas ditampilkan pada setiap akhir sesi modul sebagai glosarium untuk istilahistilah musik. Pemilihan ikon ini berdasarkan rasionalitas bahwa pengguna modul terkadang kesulitan mencari arti dari istilah-istilah musik yang banyak menggunakan istilah asing. Adanya glosarium merupakan fasilitas yang tim peneliti pertimbangkan untuk mempermudah pengguna memahami istilah-istilah musik. Selain itu, glosarium juga akan melengkapi kosa kata pengguna modul dalam menggunakan istilah-istilah musik.

\section{Hasil Tahap Development}

Untuk mengetahui hasil dari uji coba pada tahapan ini, tim peneliti menerapkan prosedur Skala Likert dengan persentase interval yang telah dihitung menjadi lima kriteria tingkat pernyataan, seperti tampak pada tabel di bawah ini, di antaranya:

Tabel 1 Interval Pernyataan

\begin{tabular}{|c|c|l|}
\hline NO & INTERVAL & \multicolumn{1}{c|}{ KETERANGAN } \\
\hline 1 & $\mathbf{0 - 2 0 \%}$ & Sangat Kurang Baik \\
\hline 2 & $\mathbf{2 1 - 4 1 \%}$ & Kurang Baik \\
\hline 3 & $\mathbf{4 2 \% - 6 2 \%}$ & Cukup Baik \\
\hline 4 & $\mathbf{6 3 \% - 8 3 \%}$ & Baik \\
\hline 5 & $\mathbf{8 4 \% - 1 0 0 \%}$ & Sangat Baik \\
\hline
\end{tabular}


a. Aspek Pemakaian Modul

Tabel 2 Respon Aspek Pemakaian Modul

\begin{tabular}{|c|c|}
\hline NO & KRITERIA PERNYATAAN \\
\hline 1 & Kemudahan pemakaian modul \\
\hline 2 & Kemudahan pemilihan materi/bahasan \\
\hline 3 & Kemudahan memahami urutan materi/bahasan \\
\hline & \begin{tabular}{r|l} 
HASIL RERATA & $88 \%$ (Sangat Baik) \\
\end{tabular} \\
\hline
\end{tabular}

b. Aspek Isi Modul

Tabel 3 Respon Aspek Isi Modul

\begin{tabular}{|c|l|}
\hline NO & \multicolumn{1}{|c|}{ KRITERIA PERNYATAAN } \\
\hline 1 & Kejelasan bahasa yang digunakan \\
\hline 2 & Tidak ada kata/kalimat yang menyimpang \\
\hline 3 & Contoh soal sesuai dengan materi yang disampaikan \\
\hline 4 & Melalui modul Anda mudah memahami materi pembelajaran \\
\hline 5 & Urutan isi materi sesuai dengan indikator \\
\hline 6 & Contoh-contoh dalam latihan jelas \\
\hline 7 & Bahasa yang digunakan mudah dipahami dan komunikatif \\
\hline 8 & Soal evaluasi (latihan) yang diberikan sesuai dengan kemampuan Anda \\
\hline 9 & $\begin{array}{l}\text { Soal evaluasi yang diberikan/sajikan berurutan sesuai dengan indikator } \\
\text { materi pelajaran }\end{array}$ \\
\hline 10 & Ketepatan Rangkuman pada setiap materi/bahasan \\
\hline \multicolumn{2}{|c|}{ HASIL RERATA } \\
\hline
\end{tabular}

c. Aspek Tampilan Modul

Tabel 4 Respon Aspek Tampilan Modul

\begin{tabular}{|c|l|}
\hline NO & \multicolumn{1}{|c|}{ KRITERIA PERNYATAAN } \\
\hline 1 & Tata letak teks dan gambar \\
\hline 2 & Kesesuaian pemilihan warna yang digunakan \\
\hline 3 & Kesesuaian pemilihan ukuran dan jenis huruf \\
\hline 4 & Kesesuaian ikon yang disajikan \\
\hline 5 & Kemenarikan tampilan ikon yang digunakan \\
\hline 6 & Kemenarikan gambar yang digunakan \\
\hline \multicolumn{2}{|c|}{ HASIL RERATA } \\
\hline
\end{tabular}

4. Hasil Uji Coba Kepada Validator

a. Respon Validator Media Pembelajaran

Tabel 5 Respon Validator Media Pembelajaran

\begin{tabular}{|c|l|}
\hline NO & \multicolumn{1}{|c|}{ KRITERIA PERNYATAAN } \\
\hline 1 & Tata letak teks dan gambar \\
\hline 2 & Kesesuaian pemilihan warna yang digunakan \\
\hline 3 & Kesesuaian pemilihan ukuran dan jenis huruf \\
\hline 4 & Kesesuaian ikon yang disajikan \\
\hline 5 & Kemenarikan tampilan ikon yang digunakan \\
\hline 6 & Kemenarikan gambar yang digunakan \\
\hline
\end{tabular}




\begin{tabular}{|c|c|}
\hline 7 & Kemudahan pemakaian modul \\
\hline 8 & Kemudahan memahami urutan materi/bahasan \\
\hline & \begin{tabular}{r|r|} 
HASIL RERATA & $82.2 \%$ (Baik) \\
\end{tabular} \\
\hline
\end{tabular}

b. Respon Validator Desain Pembelajaran

Tabel 6 Respon Validator Desain Pembelajaran

\begin{tabular}{|c|c|}
\hline NO & KRITERIA PERNYATAAN \\
\hline 1 & Kejelasan bahasa yang digunakan \\
\hline 2 & Tidak ada kata/kalimat yang menyimpang \\
\hline 3 & Contoh soal sesuai dengan materi yang disampaikan \\
\hline 4 & Melalui modul mahasiswa mudah memahami materi pembelajaran \\
\hline 5 & Urutan isi materi sesuai dengan indikator \\
\hline 6 & Contoh-contoh dalam latihan jelas \\
\hline 7 & Bahasa yang digunakan mudah dipahami dan komunikatif \\
\hline 8 & Soal evaluasi (latihan) yang diberikan sesuai dengan kemampuan \\
\hline 9 & $\begin{array}{l}\text { Soal evaluasi yang diberikan/sajikan berurutan sesuai dengan indikator } \\
\text { materi pelajaran }\end{array}$ \\
\hline 10 & Ketepatan Rangkuman pada setiap materi/bahasan \\
\hline & \begin{tabular}{r|l} 
HASIL RERATA & $83.6 \%$ (Baik) \\
\end{tabular} \\
\hline
\end{tabular}

\section{Hasil Implementation}

Pada tahap implementation, tidak dapat dilakukan sepenuhya karena tim peneliti hanya melakukan sampai tahap evaluasi formatif. Implementasi yang dilakukan bersifat tidak menyeluruh karena hanya satu modul saja yang diujicobakan di lapangan dan kendala akan waktu pelaksanaan yang tidak mungkin disesuaikan dengan jadwal mata kuliah teori musik yang berjalan. Meskipun tidak dapat dilaksanakan seluruhnya, namun tim peneliti mendapatkan gambaran sebagai bahan pengembangan dari aspek efektifitas, efisiensi, dan kemenarikan modul. Berikut adalah hasil yang diperoleh:

Tabel 7 Respon Efektifitas, Efisiensi, dan Kemenarikan Modul

\begin{tabular}{|c|c|}
\hline NO & KRITERIA PERNYATAAN \\
\hline 1 & Kemudahan pemakaian modul \\
\hline 2 & Kemudahan pemilihan materi/bahasan \\
\hline 3 & Kemudahan memahami urutan materi/bahasan \\
\hline & \begin{tabular}{r|l} 
HASIL RERATA & $79.3 \%$ (Baik) \\
\end{tabular} \\
\hline
\end{tabular}

\section{Tahap Evaluation}

Untuk mengetahui kekurangan dan kelemahan modul yang dirancang pada penelitian ini, maka tim peneliti melakukan pembandingan data hasil tahap development dan tahap implementation dengan cara menghitung data hasil respon aspek efektifitas, efisiensi, dan kemenarikan dibagi rata 3 (kriteria pernyataan). Hasilnya diketahui dengan angka $0.26 \%$. Hasil tersebut kemudian didistribusikan sebagai pengurang dari hasil respon aspek tampilan, isi, dan tampilan yang dilakukan pada tahap development. Hasil akhir dari perlakuan ini kemudian menjadi prediksi atas modul yang dikembangkan seperti tampak di bawah ini: 
a. Hasil Evaluasi Aspek Efektifitas Modul

Tabel 8 Evaluasi Aspek Efektifitas

\begin{tabular}{|c|c|}
\hline SEBELUMNYA & MENJADI \\
\hline $\mathbf{8 8 \%}$ (Sangat Baik) & $\mathbf{8 7 . 6 \%}$ (Sangat Baik) \\
\hline
\end{tabular}

b. Hasil Evaluasi Aspek Efesiensi Modul

Tabel 9 Evaluasi Aspek Efisiensi

\begin{tabular}{|c|c|}
\hline SEBELUMNYA & MENJADI \\
\hline $\mathbf{8 6 . 6 \%}$ (Sangat Baik) & $\mathbf{8 6 . 3 4 \% ~ ( S a n g a t ~ B a i k ) ~}$ \\
\hline
\end{tabular}

c. Hasil Evaluasi Aspek Tampilan Modul

Tabel 10 Evaluasi Aspek Tampilan

\begin{tabular}{|c|c|}
\hline SEBELUMNYA & MENJADI \\
\hline $\mathbf{8 3 \%}$ (Baik) & $\mathbf{8 2 . 7 6 \%}$ (Baik) \\
\hline
\end{tabular}

Berdasarkan perhitungan di atas, maka respon mahasiswa terhadap modul yang tim peneliti kembangkan adalah Baik digunakan untuk menunjang proses perkuliahan pada pembelajaran teori musik. Sedangkan berdasarkan respon validator, maka modul masih berada dalam taraf wajar dan Layak untuk digunakan dalam proses pembelajaran.

\section{Kesimpulan}

Pada proses pengembangan modul, sebaiknya dilakukan analisis kebutuhan calon pengguna modul, sehingga modul yang dikembangkan dapat berfungsi optimal, tepat sasaran, dan diterima secara nyata. Bedasarkan Hasil penelitian ini, diketahui bahwa modul yang dikembangkan berkategori Baik untuk digunakan oleh mahasiswa dalam pembelajaran teori musik dan dapat dinyatakan Layak.

\section{References}

Arsini. 2015. Peningkatan Kompetensi Profesional dan Inovasi Guru dalam Mengembangkan Video Pembelajaran Online Melalui Pembuatan Portal "Channel Pembelajaran Sains Berbasis Unity of Science" dalam Jurnal Pemikiran Agama Untuk Pemberdayaan (DIMAS) Vol. 15 No. 2. November 2015. Hal: 115-134.

Ditjen Dikdasmenum. 2004. Pedoman Umum Pemanfaatan dan Pemilihan Bahan Ajar. Jakarta: Diknas.

Ditjen PMPTK. 2008. Panduan Penulisan Modul. Jakarta: Diknas.

Fathurrohman, P. dan Sutikno M. S. 2010. Strategi Belajar Mengajar. Bandung: Refika Aditama.

Prastowo, A. 2012. Panduan Kreatif Membuat Bahan Ajar Inovatif. Yogyakarta: DIVA Press.

Kisworo, M. W. 2016. Revolusi Mengajar-Pembelajaran Aktif, Kreatif, Efektif, Menyenangkan. Jakarta: ASIK Generation.

Mudlofir, A. dan Rusydiyah, E. F. 2016. Desain Pembelajaran Inovatif-Dari Teori ke Praktik. Jakarta: PT RajaGrafindo Persada. 
Rahmawati, A. P., Pratamawati, E. W. S. D., Zandra, R. A. 2017. “M-Learning Teori Musik dalam Aplikasi Smartphone Android" dalam Journal of Art, Design, Art Education, and Culture Studies (JADECS) Vol. 2 No. 2. Desember 2017. Hal: 128-135.

Sadiman, A. S. et al. 2011. Cetakan ke-15. Media Pendidikan-Pengertian, Pengembangan, dan Pemanfaatannya. Jakarta: PT RajaGrafindo Persada.

Tegeh, I. M. dan Kirna, I. M. 2013. "Pengembangan Bahan Ajar Metode Penelitian Pendidikan dengan ADDIE Model" dalam: Jurnal Ikatan Keluarga Alumni Universitas Pendidikan Ganesha Singaraja (IKA) Vol. 11 No. 1. Maret 2013.

Universitas Negeri Padang. Panduan E-Learning-Edisi 2015. Padang: Universitas Negeri Padang.

Wati, E. R. 2016. Ragam Media Pembelajaran. Kata Pena. 